\title{
AVALIAÇÃO DA QUALIDADE MICROBIOLÓGICA DA PESCADINHA (Cysnoscion Striatus) INTEIRA E EM FILÉS NOS PRINCIPAIS PONTOS CRÍTICOS DE CONTROLE DE UMA INDÚSTRIA DE PESCADO CONGELADO *
}

\author{
ROSEMERI INÊS DAMS \\ LUÍS HENRIQUE BEIRÃO *** \\ EVANILDA TEIXEIRA ***
}

\begin{abstract}
Avaliou-se a qualidade sanitária de pescadinha (Cyanoscian striatus) mediante pesquisa de bactérias patógenas e de microrganismos indicadores de contaminação, em amostras colhidas na forma inteira e em filés, "in natura” e congeladas. Em $80 \%$ das amostras de filé e $40 \%$ do pescado inteiro "in natura", constatou-se Salmonella spp, situando-se a contagem padrão de psicrotróficos entre limites aceitáveis pelo ICMSF. Não se constatou presença de bactérias coliformes fecais, apenas coliformes totais e número não significativo de Staphylococcus aureus. Os resultados indicam deficiência de higiêne e sanificação nas operações rotineiras do processamento.
\end{abstract}

\section{INTRODUÇÃo}

As características peculiares do pescado, seu modo de captura, sua biologia e formas de processamento, tornam-no diferente de outros alimentos de origem animal,

* Trabalho realizado no Departamento de Ciência e Tecnologia de Alimentos, Universidade Federal de Santa Catarina (UFSC).

* MsC. em Ciências dos Alimentos na UFSC.

*** Prof. Dr. do Departamento de Ciência e Tecnologia de Alimentos na UFSC. 
principalmente por sua rápida deterioração. A identificação e quantificação dos riscos microbiológicos dentro do processamento do pescado congelado, assim como de qualquer outro alimento, envolve a avaliação dos riscos associados com as matérias in natura utilizadas, etapas do processamento, assim como quaisquer condições de embalagem, estocagem e vida útil do produto.

o objetivo do congelamento é reproduzir as características originais do pescado mantido congelado por longo período $(10,20)$, e o frescor essencial para oferecer alimentos de boa qualidade (20), com maior vida útil (18), pois as alterações ocorrem mais lentamente a baixas temperaturas. Contudo, microrganismos patógenos, após terem saído de seu habitat original podem permanecer em filtros de ar, no pó do chão ou da esteira, em equipamentos não limpos, contaminando os alimentos. Portanto, quando vários fatores como temperatura, atividade d'água do alimento e do meio ambiente permitem, ocorre multiplicação bacteriana.

Em condições próximas do ótimo, a fase logarítmica e o tempo de geração sendo curtos, grandes quantidades de bactérias desenvolvem-se em poucas horas (2).

A característica microbiológica do pescado pós-processamento reflete as condições higiênico-sanitárias originais do pescado, dos equipamentos, do pessoal, do tratamento térmico utilizado, do controle tempo/temperatura durante o processo, das boas práticas de fabricação do alimento e da sanificação geral na produção, assim como cuidados na embalagem e congelamento (15).

Este trabalho teve como objetivo avaliar a qualidade microbiológica de pescadinha (Cynoscion striatus), processada na forma de pescado inteiro e em filés, "in natura" e congelada.

\section{MATERIAL E MÉTODOS}

\subsection{OBTENÇÃO DAS AMOSTRAS}

As amostras de pescadinha (Cynoscion striatus) foram obtidas numa indústria de médio porte, localizada em Florianópolis, nas formas de pescado inteiro e em filés, "in natura" e congelados.

\subsection{COLETA DAS AMOSTRAS}

Dos principais pontos críticos do processamento do pescado congelado, foram retiradas as amostras para as análises 
microbiológicas. Os pontos críticos de controle foram os seguintes:

- desembarque, retirando-se as amostras de pescado inteiro in natura;

- evisceração/filetagem, retirando-se as amostras de filés;

- congelamento, retirando-se as amostras de pescado inteiro congelado.

\subsection{PLANO DE AMOSTRAGEM}

Para a pesquisa de Salmonella, Vibrio cholerae, Vibrio parahaemolyticus foi utilizado o Programa de Atributos de Duas Classes da International Commission on Microbiological Standars for Foods (ICMSF) (12), onde os dados sobre 0 atributo representam decisões de aceitação ou descarte a respeito da qualidade, expressando se um organismo em particular está presente ou não, ou em níveis superiores ao nível especificado, o qual poderá ser zero. 0 número de amostras é representado pela letra $n$ e a aceitabilidade pela letra $c$. Neste programa divide-se as unidades de amostras em duas classes:

- descartáveis (valores de c diferentes de zero);

- aceitáveis (valores de $\boldsymbol{c}$ iguais a zero).

Prova ausência/presença: Salmonella, Vibrio parahaemolyticus, Vibrio cholerae, onde $\boldsymbol{n}=5$ (cinco) e $\boldsymbol{c}=\odot$ (zero).

Para coliformes de origem fecal e Escherichia coli, contagem padrão em placa de psicrotróficos a $25^{\circ} \mathrm{C}$ e Staphylococcus aureus foi utilizado o Programa de Atributos de Três Classes (12). Neste programa a qualidade de um produto pode dividirse em três classes e são definidos dois níveis de contagem, $m$ e $\boldsymbol{M}$. Considera-se $\boldsymbol{m}$ o nível que o microrganismo poderá alcançar no alimento, separando assim, as amostras aceitáveis das temporariamente aceitáveis. 0 nível $\boldsymbol{M}$ é um nível de contaminação perigoso devido a procedimentos sanitários deficientes, assim todas as amostras que apresentam contagens superiores a este são descartadas. Este nível pode ser considerado como índice higiênico geral, relacionando-se as taxas de bactérias indicadoras como condição higiênica claramente inaceitável, além de relacionar-se também à alteração detectável ou com diminuição da vida útil a um período curto inaceitável. Há, portanto, divisão das unidades de amostra em três classes: totalmente aceitáveis, temporariamente aceitáveis e descartáveis. 
Para os microragnismos indicadores foi estabelecido como $\boldsymbol{n}=$ 5 (cinco) e o número aceitável $\boldsymbol{c}$, onde se admite resultado acima do limite aceitável $m=3$ (três). A ICMSF (12) estabelece os níveis de contagem $\boldsymbol{m}$ e $\boldsymbol{M}$ indicados na Tabela 1.

TABELA 1 - NÍVEIS DE CONTAGEM $m$ E $M$ PARA 0 PROGRAMA DE ATRIBUTOS DE 3 CLASSES ESTABELECIDOS PELO ICMSF

\begin{tabular}{lcc}
\hline & $\begin{array}{c}\boldsymbol{m}^{*} \\
(\mathrm{UFC} / \mathrm{g})\end{array}$ & $\begin{array}{c}\boldsymbol{M} \\
(\mathrm{UFC} / \mathrm{g})\end{array}$ \\
\hline $\begin{array}{l}\text { Contagem padrão em } \\
\text { placa a } 25^{\circ} \mathrm{C}\end{array}$ & $10^{6}$ & $10^{7}$ \\
$\begin{array}{l}\text { Bactérias coliformes } \\
\text { de origem fecal }\end{array}$ & 4 & 400 \\
\begin{tabular}{l} 
Staphylococcus aureus \\
\hline
\end{tabular}
\end{tabular}

*UFC = Unidade formadora de colônia.

\subsection{METODOLOGIA}

2.4.1 Preparação do homogeneizado da amostra

A amostra foi homogeneizada conforme recomendação da American Public Health Association (APHA) (8), utilizando-se como solução diluente água peptonada a $\odot, 1 \%$.

2.4.2 Contagem total de psicrotróficos a $25^{\circ} \mathrm{C}$

A contagem total de psicrotróficos foi efetuada a $25^{\circ} \mathrm{C}$, leitura em 24/48 horas, conforme recomendações da ICMSF (12) e APHA (19), pois esta temperatura é indicadora de alteração incipiente, devido à natureza psicrofílica da microbiota deteriorante do pescado e seus derivados. 


\subsubsection{Salmonella spp}

Para a pesquisa da presença/ausência de Salmonella spp, utilizou-se a técnica recomendada pelo APHA (19) com as seguintes modificações:

* para enriquecimento seletivo foram utilizados os meios Caldo Tetrationato e Caldo Rappaport Vassiliadis e temperatura de incubação a $35^{\circ} \mathrm{C}$ por 24 horas (20);

* no isolamento seletivo utilizou-se os meios Ágar Salmonella-Shigela, também denominado de ágar SS (7) e Ágar verde Brilhante (BGA), recomendado pelo APHA (19). A temperatura de incubação foi de $35^{\circ} \mathrm{C}$ por 24 horas.

2.4.4 Staphylococcus aureus

Utilizou-se a metodologia recomendada pela APHA (4).

2.4.5 Bactérias coliformes de origem fecal

Utilizou-se a metodologia recomendada pela APHA (11).

2.4.6 Vibrio cholerae

Utilizou-se a metodologia recomendada pelo Foods and Drugs Administration (FDA) (16).

\subsubsection{Vibrio parahaemolyticus}

Utilizou-se a metodologia recomendada pela APHA (14).

\section{RESULTADOS E DISCUSSÃo}

\subsection{RESULTADOS}

Na Tabela 2 estão apresentados os resultados das análises microbiológicas realizadas nas amostras retiradas dos principais pontos críticos de controle no processamento do pescado congelado. 
TABELA 2 - RESULTADOS DAS ANÁLISES MICROBIOLÓGICAS REALIZADAS NOS PRINCIPAIS PONTOS CRÍTICOS NO PROCESSAMENTO DO PESCADO CONGELADO

\begin{tabular}{|c|c|c|c|c|c|c|}
\hline Amostra & $\begin{array}{l}\text { Microrganismos } \\
\text { psicrotróficos a } \\
25^{\circ} \mathrm{C}(\mathrm{UFC} / \mathrm{g}) \\
\end{array}$ & $\begin{array}{l}\text { Bactérias de origem } \\
\text { fecal (NMP/g) }\end{array}$ & $\begin{array}{l}\text { Salmonella spp } \\
\text { (ausência/ } \\
\text { presença) em } 25 \mathrm{~g} \\
\end{array}$ & $\begin{array}{l}\text { Vibrio cholerae } \\
\text { (ausência/ } \\
\text { presença) } \\
\end{array}$ & $\begin{array}{c}\text { Vibrio parahaemolyticus } \\
\text { (ausência/ } \\
\text { presença) } \\
\end{array}$ & $\begin{array}{c}\text { Staphylococcus aureus } \\
\text { (UFC/g) }\end{array}$ \\
\hline $\begin{array}{l}\text { pescado } \\
\text { inteiro in natura }\end{array}$ & $\begin{array}{c}3.10^{5} \\
3,4 \cdot 10^{5} \\
7,15 \cdot 10^{5} \\
7,15 \cdot 10^{5} \\
7,35 \cdot 10^{5}\end{array}$ & $\begin{array}{l}2,3 \cdot 10^{3} \\
9,3 \cdot 10^{3} \\
9,3 \cdot 10^{3} \\
2,4.10^{5} \\
<3\end{array}$ & $\begin{array}{l}\text { ausência } \\
\text { presença } \\
\text { ausência } \\
\text { ausência } \\
\text { ausência }\end{array}$ & $\begin{array}{l}\text { ausência } \\
\text { ausência } \\
\text { ausência } \\
\text { ausência } \\
\text { ausência }\end{array}$ & $\begin{array}{l}\text { ausência } \\
\text { ausência } \\
\text { ausência } \\
\text { ausência } \\
\text { ausência }\end{array}$ & $\begin{array}{l}<20 \\
<20 \\
<20 \\
<20 \\
<20\end{array}$ \\
\hline $\begin{array}{l}\text { pescado inteiro } \\
\text { congelado }\end{array}$ & $\begin{array}{c}1,1.10^{6} \\
4,18 \cdot 10^{6} \\
5,41.10^{6} \\
5,62.10^{6} \\
5,64.10^{6}\end{array}$ & $\begin{array}{c}2,3.10^{3} \\
9,10.10^{2} \\
4,10.10^{2} \\
\quad<3 \\
\quad<3\end{array}$ & $\begin{array}{l}\text { presença } \\
\text { presença } \\
\text { ausência } \\
\text { ausência } \\
\text { ausência }\end{array}$ & $\begin{array}{l}\text { ausência } \\
\text { ausência } \\
\text { ausência } \\
\text { ausência } \\
\text { ausência }\end{array}$ & $\begin{array}{l}\text { ausência } \\
\text { ausência } \\
\text { ausência } \\
\text { ausência } \\
\text { ausência }\end{array}$ & $\begin{array}{l}<20 \\
<20 \\
<20 \\
<20 \\
<20\end{array}$ \\
\hline filé congelado & $\begin{array}{c}2,7.10^{5} \\
4,18 \cdot 10^{6} \\
5,41 \cdot 10^{6} \\
5,62 \cdot 10^{6} \\
5,64 \cdot 10^{6}\end{array}$ & $\begin{array}{c}4.10^{2} \\
9.10^{2} \\
2,4.10^{5} \\
2,4.10^{5} \\
9.10^{2}\end{array}$ & $\begin{array}{l}\text { ausência } \\
\text { presença } \\
\text { presença } \\
\text { presença } \\
\text { presença }\end{array}$ & $\begin{array}{l}\text { ausência } \\
\text { ausência } \\
\text { ausência } \\
\text { ausência } \\
\text { ausência }\end{array}$ & $\begin{array}{l}\text { ausência } \\
\text { ausência } \\
\text { ausência } \\
\text { ausência } \\
\text { ausência }\end{array}$ & $\begin{array}{l}<20 \\
<20 \\
<20 \\
<20 \\
10 .{ }^{2}\end{array}$ \\
\hline
\end{tabular}

NMP = Número mais provável

UFC = Unidade formatora de colônia. 


\subsection{DISCUSSÃO}

\subsubsection{Contagem padrão a $25^{\circ} \mathrm{C}$}

A contagem de aeróbios viáveis, também denominada de contagem Padrão em placa, é considerada como indicador da vida útil ou da qualidade do produto, ou do controle sanitário exercido no processamento, refletindo assim se os sistemas de fabricação, na indústria do pescado, são aceitáveis ou não $(12,13)$. os resultados apresentados na Tabela 1 mostram que há aumento progressivo da população psicrotrófica durante o processamento. 0 pescado in natura, quando do seu desembarque, apresentou níveis baixos de população psicrotrófica no total de amostras analisadas, enquanto que todas as amostras de filés congelados apresentaram níveis mais elevados. Comparando-se os padrões pré-estabelecidos, sugeridos pela ICMSF (12), onde $m=10^{6}$ e $M=10^{7}$, sendo que no máximo 3 (três) amostras podem atingir o valor de $10^{6} \mathrm{e}$ nenhuma pode ultrapassar o valor de $10^{7}$, nota-se que todas as amostras de filé congelado estão além dos limites permitidos. As amostras de pescado inteiro congelado encontram-se dentro dos limites propostos

pela ICMSF (12), no qual até 3 (três) amostras das 5 (cinco) analisadas podem estar além de $10^{6}$. Entretanto, os valores obtidos indicam que as condições nas quais o pescado foi manipulado, além das condições sanitárias da planta processadora, não são adequadas. Muitos microrganismos psicrotróficos, quando presentes em grande número, podem causar variedade de flavors desagradáveis, assim como defeitos de textura nos alimentos. Seu crescimento é altamente dependente da temperatura e torna-se gradativamente menor à medida que esta é reduzida. Sua presença nos pescados é importante quando estes alimentos são descongelados e algumas vezes reembalados, e vendidos como refrigerados (6).

\subsubsection{Bactérias coliformes de origem fecal}

A legislação brasileira em vigor (5) determina para pescados e produtos de pesca, especificamente pescado in natura, fresco, refrigerado, congelado, inclusive filetados e empanados o valor máximo de wazzu $10^{2}$ bactérias coliformes de origem fecal. Portanto, os resultados encontrados estão condizentes com a legislação em vigor, uma vez que a presença de bactérias coliformes de origem fecal não foi detectada, mas apenas bactérias coliformes. Estes resultados também estão de acordo com a ICMSF (12), cujos padrões sugeridos estão entre 4 e 400 bactérias coliformes de origem fecal. Contudo, a presença do grupo coliforme pode ser considerada como indicador útil da contaminação pós-sanificação e pósprocessamento, embora sua especificidade esteja diminuída pelo anonimato de seus membros individuais, podendo conter 
membros não entéricos do gênero, como Serratia e Aeromonas. Assim, práticas que permitam sua presença em tais circunstâncias não são condizentes com padrões de boa sanificação, requeridos para as operações de processamento de alimentos (11).

\subsubsection{Pesquisa de Salmonella spp}

Tanto a legislação brasileira (5) como a ICMSF (12), estabelecem a ausência de Salmonella spp em $25 \mathrm{~g}$ para pescados e produtos derivados. Os resultados indicam sua presença em $80 \%$ das amostras de filé congelado, $40 \%$ do pescado inteiro congelado e $20 \%$ do pescado inteiro in natura. Em estudos realizados com merluza (Merluccius), foi constatada a presença de Salmonella spp em 6,66\% das amostras de filés, postas e pescado inteiro congelados (22). Pressupõe-se que todas as espécies e cepas de Salmonella spp possam ser patogênicas ao homem, sendo portanto, sua presença em alimento inadmissível (13).

Sabe-se que as Salmonellas que contaminam os alimentos são provenientes principalmente de animais (localizadas em seus tratos intestinais) e do próprio homem, podendo proceder tanto de portadores doentes como assintomáticos $(9,13)$. Assim, a salmonelose continua a ser uma das principais doenças de origem alimentar em todo o mundo. A presença de Salmonella numa linha de processamento de pescado congelado pode ser devido a várias fontes, como a contaminação por águas poluídas, estocagem inadequada em locais não sanitizados, contaminação cruzada do pescado limpo e eviscerado com resíduos, contato com moscas, insetos e do próprio manipulador que poderá ser assintomático.

\subsubsection{Pesquisa de Vibrio cholerae e Vibrio parahaemolyticus}

os resultados apresentados na Tabela 2 mostram que não foi constatada a presença de Vibrio parahaemolyticus e vibrio cholerae em nenhuma das amostras analisadas. A maioria destes é considerada psicrotrófica, contudo, há um grupo de vibriões mesófilos presentes no meio ambiente marinho costeiro e em alguns mananciais doces, que podem causar doenças ao homem. Estas bactérias são levemente halófilas, facilmente destruídas por temperaturas acima de $55^{\circ} \mathrm{C}$, mas têm a habilidade de crescerem muito rapidamente quando a temperatura e condições nutricionais são adequadas. A principal causa de contaminações, cuja fonte tem sido registrada nos alimentos marinhos, são o vibrio parahaemolyticus, seguido pelo Vibrio cholerae (14). A gastroenterite causada pelo vibrio parahaemolyticus é contraída principalmente por alimentos marinhos, e quando outros alimentos estão envolvidos, houve contaminação cruzada 
com produtos marinhos. 0 meio ambiente deste agente etiológico é o mar, sendo comum em águas costeiras e oceânicas. Os principais alimentos envolvidos são ostras, camarões, lagostas, mariscos e caranquejos (13). As infecções são causadas principalmente pelo consumo destes alimentos crus, mal cozidos, contaminados ou recontaminados (14). Além de sua sobrevivência em águas marinhas, deve-se considerar também fatores como armazenamento do pescado no estado congelado, o qual pode afetar significativamente a sobrevivência de Vibrio parahaemolyticus e Vibrio cholerae, pois o congelamento limita a atividade d'água (aw) e a temperatura do produto é muito baixa para permitir o crescimento microbiano. Assim, o congelamento poderá ser letal a muitas bactérias presentes nos alimentos.

\subsubsection{Staphylococcus aureus}

A legislação brasileira (5) em vigor estabelece o valor máximo de $10^{2}$ ufc/g de Staphylococcus aureus para pescado e derivados. Os resultados encontrados mostram sua ausência em praticamente todas as amostras, com apenas uma de filé atingindo o valor máximo permitido. Estes resultados também estão de acordo com os limites estabelecidos pela ICMSF (12), no qual das 5 (cinco) amostras analisadas, até 3 (três) podem ultrapassar o limite de $10^{3}$ ufc/g e o valor de $\boldsymbol{M}$ é $2.10^{3}$ ufc/g. Contudo, estes resultados podem ser conseqüência da injúria, provocada pelo congelamento, à célula bacteriana, uma vez que a sanificação imprópria e as operações de evisceração e filetagem estão, geralmente, associadas com este organismo. Estudos mostram que as mãos, o nariz e a pele de manipuladores são principais fontes de S.aureus (3), e que a maioria dos casos de intoxicação estafilocócica provém dos manipuladores de alimentos (1). Em estudos feitos com blocos de pescado congelado, foi constatado $S$.aureus coagulase positiva em $19 \%$ dos blocos analisados, sendo que a contagem máxima obtida pelos autores não excedeu 24 organismos/g, os quais estão de acordo com os critérios estabelecidos pela $\operatorname{ICMSF}(12,15)$.

\section{CONCLUSÃO}

os resultados indicam que há grande deficiência quanto à higiene e sanificação na planta processadora de pescado congelado, pois constatou-se a presença de Salmonella spp em todos os principais pontos críticos de controle. Tal fato indica claramente a necessidade de orientar os manipuladores quanto aos seus hábitos higiênico-sanitários, além de significativa melhoria nas operações de limpeza e sanificação, de modo a serem eliminados os riscos 
microbiológicos evidenciados pelas análises, embora muitos resultados estejam dentro dos limites propostos pela ICMSF, assim como pela legislação brasileira.

\section{Abstract}

The sanitary quality of whitting fish (Cynoscion striatus) was evaluated through research on patogens microrganisms and on contamination indicators in "in natura" samples, both whole fish and frozen fillets. Salmonella spp was found in $80 \%$ of the fillets and in $40 \%$ of the whole "in natura" fish. The counting of psichrotrophics microrganisms was between acceptable limits, as proposed by ICMSF. Results were negative for fecal coliforms, but positive for total coliforms, as well as for a not significant number of staphylococcus aureus. There is a clear evidence of higienic and sanitization deficiency in the fish handling and processing.

\section{REFERÊNCIAS BIBLIOGRÁFICAS}

1 BERGDOLL, M.S. Staphyloccal intoxications. In: RIEHMANN, H., BRYAN, F.L. Food-borne infections and intoxications. London : Academic Press, 1979. p. 443-494

2 BRYAN, F.L. Microbiological food hazards today based on epidemiological information. Food Technology, Chigaco, p. 52-66, Sept. 1974.

3 BRYAN, F.L. Sea food-transmitted infections and intoxications in recent years. In: KRAMER, D.E., LISTON, $\mathrm{J}$. Sea food quality determination. New York : Elsevier, 1987. v. 15

4 BENNETT, R.W., NOTERMANS, S., TATINI, S.R. Staphylococcal enteroroxins. In: VANDERZANT, C., SPLITTSTOESSER, D.F. Compendium of methods for the microbiological examination of foods. Washington : APHA, 1992. $1219 \mathrm{p}$.

5 BRASIL. Ministério da Saúde. Divisão Nacional de Vigilância Sanitária de Alimentos. Portaria $n^{\circ} 01$ de 28 de janeiro de 1987. Diário Oficial [da República Federativa do Brasil], Brasília, 12 fev. 1987.

6 COUSIN, M.A., JAY, J.M., VASAVADA, P.C. Psychrotrophic microrganisms. In: VANDERZANT, C., SPLITTSTOESSER, D.F. Compendium of methods for the microbiological examination of foods. Washington : APHA, 1992. p. 153-164 
7 DIFCO Laboratories. Difco manual of dehydrated culture media and reagents for microbiological and critical laboratory procedures. Detroit, 1984.

8 FLOWERS, R.S., GECAN, J.S., PUSCH, D.J. General laboratory procedures. In: VANDERZANT, C., SPLITTSTOESSER, D.F. Compendium of methods for the examination of foods. Washington : APHA, 1992.

$1219 \mathrm{p}$.

9 FRAZIER, W.C. Microbiologia de los alimentos. Zaragoza : Acribia, 1976. $512 \mathrm{p}$.

10 GRUDA, Z., POSTOLSKI, J. Tecnologia de la congelacion de los alimentos. Zaragoza : Acribia, 1986. $631 \mathrm{p}$.

11 HITCHINS, A., HARTMAN, P.A., TODD, E.C.D. Coliforms: Escherichia coli and its toxins. In: VANDERZANT, C., SPLITTSTOESSER, D.F. Compendium of methods for the examination of foods. Washington : APHA, 1992. p. 325-367.

12 ICMSF. International Commission on Microbiological Standards for Foods. Microrganismos de los alimentos: metodos de muestro. In: VANDERZANT, C., SPLITTSTOESSER, D.F. Para análisis microbiolócicos: princípios y aplicaciones especificas. Zaragoza : Acribia, 1981. v. 2

13 JAY, J.M. Modern food microbiology. New York : Van Nostrand Reinhold, 1986. $641 \mathrm{p}$.

14 KAYSNES, C.A., TAMPLIN, M.L., TWEDT, R.M. Vibrio. In: VANDERZANT, C., SPLITTSTOESSER, D.F. Compendium of methods for the examination of foods. Washington : APHA, 1992. p.451-469

15 LISTON, J. Microbial hazards of sea food consumption. Food Technology, p. 56-62, Dec. 1990.

16 MADDEN, J.M., MCCARDELL, B.A., BOUTIN, B.K. Isolation and identication of Vibrio cholerae. In: Bacteriological and identication of the dividion of microbiology center fos food safety and applied nutriation. Washington : FDA, 1984 .

17 PETERSON, A.C., GUNNERSON, R.E. Microbiological critical control points in frozen foods. Food Technology, Chigaco, p. 37-44, Sept., 1974. 
18 REID, D.S. Ottimizing the quality of frozen foods. Food Technology, p. 78-82, July 1990.

19 RUSSEL, S.F., D'AOUST, J., ANDREWS, W.H., BAILEY, J.S. Salmonella. In: VANDERZANT, C., SPLITTSTOESSER, D.F. Compendium of methods for the examination of foods. Washington : APHA, 1992. p. 371- 415

20 TANAKA, T. Freezing preservation of fish and other marine products. In: KADOTA, H., HASHIMOTO, K., KAYAMA, M. TOKUNAGA, T. Science of processing marine food products. Kanagawa : International Fisheries Training Centre, 1992. $172 \mathrm{p}$.

21 VASSILIADIS, P.I., TRICHOPOULOS, D., PAPADAKIS, J., KALAPOTHAKI, V., ZAVITSANOS, X. Salmonella isolation with Rappaport's enrichment medium of different compositions. Zol. Bakteriol. Microbiol. Hyg., n. 173, p. 382-389, 1981.

22 VILLAR, L.M.P. Investigaciones sobre la calidad bacteriologica de la merluza (Merluccius sp) congelada. Archivos de Zootecnia, v. 24, n. 93, p. 3-31, 1975. 